\title{
RECONFIGURAÇÃO DO ESTADO E O NOVO ORDENAMENTO LEGAL E POLÍTICAS PARA O ENSINO MÉDIO NO BRASIL NO PERÍODO DE 1995-2015
}

\author{
RECONFIGURATION OF THE STATE AND THE NEW LEGAL ORDER AND \\ POLICIES FOR HIGH SCHOOL IN BRAZIL IN THE PERIOD 1995-2015
}

MORAIS, Edima Veronica ${ }^{1}$

\begin{abstract}
RESUMO
Este trabalho busca trazer um estudo comparado entre as políticas desenvolvidas no Brasil para a Educação Profissional, que tem como público alvo a juventude, durante os Governos de Fernando Henrique Cardoso, de Luís Inácio (Lula) da Silva e do Governo da Presidente Dilma Roussef. Nesse sentido, buscamos compreender em que medida as ações desenvolvidas por estes governos, através dos programas implementados durante as referidas gestões, contribuíram de fato para o fortalecimento e melhoria na qualidade do ensino médio e como a qualificação profissional em certa medida atende as demandas de formação da juventude trabalhadora. Importante salientar que compreender a trajetória que as políticas públicas para o Ensino Médio percorreram ao longo dos últimos anos é fundamental para entendermos o que está acontecendo neste momento no Brasil.
\end{abstract}

PalaVras-Chave: Ensino Médio; Políticas Educacionais; Formação da Juventude; Qualificação profissional; Reformas Educacionais.

\section{ABSTRACT}

This article presents a comparative study between the policies for Vocational Education developed in Brazil during the administrations of former Presidents Fernando Henrique Cardoso, Luís Inacio (Lula) da Silva and Dilma Roussef. In this sense, we seek to understand to what extent the actions developed by these governments, through the programs implemented during their administrations, have in fact contributed to the strengthening and improvement in the quality of high school education and how professional qualification, to some extent, meets the demands of training working youth. It is important to emphasize that, understanding the trajectory that public policies for high school had over the last few years is fundamental to comprehend what is happening nowadays in Brazil.

KeYwords: High School; Educational Policies; Youth Formation; Professional qualification; Educational Reforms.

\footnotetext{
${ }^{1}$ Universidade Federal de Pernambuco (UFPE) / Programa de Pós-Graduação da Universidade Federal de Pernambuco - Campus Agreste. Caruaru, PE, Brasil. e-mail: edimamorais@hotmail.com
} 
DOI: $10.12957 / \mathrm{e}-\mathrm{mosaicos} .2020 .46488$

\section{INTRODUÇÃO}

Neste trabalho, realizamos um estudo comparado das políticas educacionais, para o Ensino Médio, desenvolvidas durante os governos de Fernando Henrique Cardoso, do Presidente Luís Inácio (Lula) da Silva e do Governo da Presidenta Dilma Roussef. Assim, compreender a trajetória das políticas públicas para o Ensino Médio ao longo dos últimos anos é fundamental para entendermos como se configura hoje, no Brasil, as políticas para essa etapa de ensino que historicamente foi e é palco de disputa, entre diferentes grupos políticos. De um lado, temos grupos mais vinculados aos setores representantes da iniciativa privada e, de outro, os que defendem uma concepção de educação que visa atender a interesses e necessidades da classe trabalhadora, a partir da construção de um currículo que alie de forma orgânica ciência, tecnologia, cultura e trabalho. Ou seja, um projeto que tem como finalidade a formação integral dos jovens estudantes da classe trabalhadora, equilibrando, de modo justo, o desenvolvimento da capacidade desses jovens de trabalhar manualmente e o desenvolvimento das capacidades de trabalho intelectual.

Pensamos ser importante conhecer como as políticas referentes a esta etapa de ensino se desenvolveram nos últimos anos, especificamente durante os governos do Partido dos Trabalhadores (PT) e que, no momento atual, após a destituição de uma presidente eleita, através de um golpe jurídico-parlamentar abriu caminho para implementação de políticas que destroem direitos conquistados da classe trabalhadora, aprofunda as desigualdades e levou ao poder um grupo político que tem como fundamento a necropolítica entendida como um poder que decide e dita de forma autoritária e violenta quem pode viver e quem deve morrer subjugando a vida ao poder da morte. (MBEMBE, 2016).

Diante disto, este trabalho vem tratar de questões referentes ao conjunto de reformas postas ao Estado em decorrência da nova configuração social estabelecida pela reestruturação da produção, e que repercutiram de maneira preponderante sobre a educação provocando a construção de um novo ordenamento legal que subsidiaram as reformas educacionais no Brasil, mais especificamente o que diz respeito ao Ensino Médio.

\section{O Ensino Médio "DeSintegrado" no governo CaRdoso (1995/ 2002)}

A década de 1990 foi marcada por um conjunto de reformas que objetivaram reconfigurar o papel do Estado, atribuindo-lhes novas competências e funções, contribuindo para uma maior participação do setor privado em setores antes tidos como exclusivo do setor estatal. As reformas realizadas em diversos países do mundo procuraram fortalecer sua "função reguladora em detrimento de atividades relacionadas à produção de bens e serviços para o mercado" (FERREIRA, 2009, p. 255). Essas reformas têm seu fundamento nas políticas neoliberais adotadas a partir 
da década de 1980 sob a orientação do Consenso de Washington, que recomendava às nações emergentes a renúncia por parte do Estado de qualquer intervenção na economia, garantindo a manutenção das regras e da ordem, particularmente o respeito à propriedade privada e o cumprimento das obrigações contratuais. Nesta seção, trataremos dos fundamentos das reformas do ensino empreendidas durante 0 governo de Fernando Henrique Cardoso.

A total associação dos países da América Latina ao Consenso de Washington trouxe como consequência uma "semirrecessão crônica" que perdura até hoje. Essa adesão ao receituário neoliberal levou os países dessa região a um crescimento do PIB a algo que não chegou a $3 \%$ ao ano. Enquanto nos países que o rejeitaram, a expansão média do PIB circunscreveu-se entre 7\% e 9\% (Taiwan, Coreia do Sul, Hong Kong, Cingapura e ainda China e İ́ndia) (MAGALHÃES, 2010).

No Brasil, o receituário neoliberal foi adotado, inicialmente, no governo de Fernando Collor de Mello e depois com o governo de Fernando Henrique Cardoso. Ambos implantaram um modelo econômico baseado nas relações de força do mercado e no papel regulador do Estado, promovendo uma avalanche de privatizações de empresas, bens e serviços. Tal política procurou se adequar ao modelo ditado pelos organismos internacionais, demonstrando a característica histórica da burguesia brasileira de subordinação aos grandes centros hegemônicos, em que as "classes dominantes se associam ativamente, mas de maneira subordinada aos países economicamente hegemônicos, abrindo espaço para expansão do capital, notadamente o capital financeiro tendo como fim a especulação para garantir lucros independentemente da produção". (CIAVATTA; FRIGOTTO, 2011, p. 621).

Com o discurso de preparar o Brasil para enfrentar o século XXI, foram tomadas medidas que tentavam redefinir a modernização historicamente desenvolvida no país, assentada num modelo de desenvolvimento conduzido pelo Estado. Em relação às reformas educacionais no governo FHC, estas foram marcadas por práticas descentralizadoras, de controle e de privatizações.

Assim, como ponto de partida para o debate das reformas educacionais no Brasil da década de 1990 poderíamos apreender as reformas constitucionais realizadas no período. A Constituição Federal de 1988, por exemplo, expressa uma concepção ampliada de educação, considerada pela literatura como um avanço importante. No seu artigo $6^{\circ}, 0$ texto constitucional concebe a educação como um direito social que visa ao "pleno desenvolvimento da pessoa, seu preparo para o exercício da cidadania e sua qualificação para o trabalho" (BRASIL, 2006, p. 134). Entretanto, essa nova concepção de educação é tão ampla que abre espaço para diversas interpretações, inclusive no sentido mais conservador.

Em relação ao Ensino Médio, por exemplo, essa concepção ampliada influenciou a definição desse nível de ensino como etapa complementar da educação básica, para o qual o Estado tem o dever de assegurar a "progressiva extensão da obrigatoriedade do Ensino Médio gratuito" indicando para a ampliação da oferta de vagas. Entretanto, 
por cumprimento às orientações dos organismos multilaterais, a emenda no 14/1996 alterou o texto constitucional para "progressiva universalização do Ensino Médio gratuito" (BRASIL, 2006, p. 134) criando o Fundo de Manutenção e Desenvolvimento do Ensino Fundamental e de Valorização do Magistério (FUNDEF) que destinou recursos para Estados e Municípios proporcionalmente ao número de alunos do Ensino Fundamental, concentrando assim a aplicação dos recursos nesse nível de ensino.

Consideramos, portanto, que a garantia de universalização pressupõe uma expansão democrática e com qualidade, o que, no Brasil, torna-se um desafio político muito difícil de ser enfrentado, demonstrado pelo fato de que até hoje esse problema não foi equacionado.

Desde o final da década de 1980, um conjunto de projetos, frutos da disputa do direito básico à educação e guiada pela necessidade de construção de uma educação unitária, laica, gratuita, de formação politécnica e omnilateral, estava sendo gestado no Brasil. Durante um longo processo, esse movimento deu origem à Lei de Diretrizes e Bases da Educação, a Lei 9394/1996, cuja elaboração se configurou de forma conflituosa, resultado de tensões políticas. ${ }^{2}$ O documento aprovado, contudo, representou a vitória de segmentos conservadores "que conseguiram aprovar uma lei minimalista, por cujas lacunas adentraram muitas reformas" (RAMOS, 2010, p. 43). Dessa maneira, a LDBEN/1996 manteve o texto constitucional sobre a "progressiva extensão e obrigatoriedade do Ensino Médio gratuito" como já citado acima, mas foi além ao definir, no art. 35, o Ensino Médio como etapa final da Educação Básica com duração mínima de três anos (BRASIL, 2017, p.24).

A integração do Ensino Médio à Educação Básica significou um comprometimento com uma formação mais ampla e complexa. Para Kuenzer (2010), a vinculação de todas as modalidades de ensino dentro da concepção de educação básica afirmando sua integração e consolidando sua organicidade resulta da compreensão de educação como totalidade. Isto se relaciona com a ideia de que a formação do estudante acontece de forma contínua e ampla não admitindo uma formação fragmentada e estanque. Ademais, ao organizar a educação básica como um sistema integrado não se "admite formas paralelas que comprometam a assumida integração entre as etapas e modalidades de ensino (...)" (FERREIRA, 2011, p. 510).

Importante citar ainda que no Plano Nacional de Educação (2001-2011) foram colocados objetivos e metas para Educação que deveriam ser alcançados no prazo de dez anos. Em relação ao Ensino Médio, entre outras, a meta até 2011 era oferecer num prazo de cinco anos $50 \%$ e, em dez anos, $100 \%$ das vagas que atenderiam à demanda deste nível de ensino "em decorrência da universalização e regularização do fluxo de alunos no Ensino Fundamental" (BRASIL, 2001, p.26). Esse documento (PNE/2001-2011) reconheceu que entre as diferentes etapas de ensino, o Ensino Médio foi o que mais sofreu com a ausência dos caminhos a serem seguidos em relação

\footnotetext{
2 Para maiores informações sobre os antecedentes da LDB ver: SAVIANI, D. Da nova LDB ao FUNDEB: por uma outra política educacional. Campinas, SP: Autores Associados, 2008.
} 
aos seus objetivos e à organização tendo previsto que este quadro seria superado pela implementação das Diretrizes Curriculares para o Ensino Médio (DCNEM).

As DCNEM foram instituídas através da Resolução 03/1998 do CNE. Com a implantação dessa resolução, o MEC começou a veicular pela mídia que o Ensino Médio "agora é para a vida", demonstrando uma clara oposição à proposta anterior, que em tese teria o objetivo de preparação para o mercado de trabalho. As Diretrizes Curriculares de 1998 buscaram significar que a formação humana deveria ser compreendida como resultado da articulação das finalidades da educação para cidadania e para o trabalho (KUENZER, 2000).

Entretanto, controversamente, o governo FHC em 1997 lançou o decreto 2.208/1997 reeditando a lei 5792/1971. Nesta direção, podemos evidenciar no mínimo dois modelos pedagógicos conflitantes. Essa concepção de Ensino Médio profissionalizante, segundo Saviani (1997), é entendida como uma formação na perspectiva de "adestramento", pois não se consideram os fundamentos que orientam a atividade técnica. Por isso mesmo, esse modelo de ensino técnico expressa o que foi denominado por Ramos (2006) por "Pedagogia das Competências"3. O referido decreto se configurou, por conseguinte, numa direção contrária à LDBEN/1996 afirmando que a formação técnica deveria se organizar independentemente do ensino médio regular, restaurando a dualidade histórica entre Ensino Geral e Ensino Profissional.

Cabe ainda mencionar que as Diretrizes Curriculares Nacionais para o Ensino Médio têm como finalidade construir um conjunto de situações que permitam a geração de competências. Segundo Ramos (2011), trata-se na verdade de uma releitura das quatro grandes necessidades de aprendizagens relatadas na Reunião Internacional sobre Educação para o Século XXI da UNESCO, o conhecido Relatório Jacques Delors: aprender a conhecer, aprender a fazer, aprender a conviver e aprender a ser, demonstrando como as políticas educacionais brasileiras nos últimos anos se coadunam com as indicações propostas pelos organismos internacionais.

Historicamente o Ensino Médio esteve subordinado aos interesses do mercado de trabalho (RAMOS, 2004), mesmo diante da fragilidade deste frente às constantes crises do capitalismo. Paradoxalmente evidenciamos a partir da LDBEN de 1996, que a educação básica tem por finalidade, de acordo com o artigo 22, "desenvolver o educando, assegurar-Ihe a formação indispensável para o exercício da cidadania e fornece-lhes meios para progredir no trabalho e em estudos posteriores" (BRASIL, 2017, p. 17). Esta última finalidade deve ser desenvolvida precipuamente pelo Ensino Médio, uma vez que entre suas finalidades específicas incluem-se "a preparação básica para o trabalho e a cidadania do educando". (BRASIL, 2017, p.24). Segundo Ramos

\footnotetext{
${ }^{3}$ Competência é a capacidade que os trabalhadores têm de enfrentar situações e acontecimentos próprios de um campo profissional, com iniciativa e responsabilidade, guiados por uma inteligência prática do que está ocorrendo coordenando-se com outros atores para mobilizar suas próprias capacidades (ZARIFIAN apud RAMOS, 2006).
} 
DOI: $10.12957 /$ e-mosaicos.2020.46488

(2010), isso tem a ver com o conceito de "empregabilidade" 4, amplamente disseminado pelos "homens de negócio" e seus meios de comunicação. Isso significa desenvolver habilidades flexíveis que permitam aos indivíduos se adaptarem facilmente às incertezas do mundo contemporâneo.

As políticas educacionais, no Brasil, após a promulgação da LDBEN/1996 apresentam uma sintonia com o atual modelo econômico, que se identifica como sendo o Modelo Econômico Liberal-Periférico no Brasil ${ }^{5}$ (FILGUEIRAS et al., 2010). Em relação ao Ensino Médio, tem sua expressão na Resolução 03/1998 do CNE que institui as Diretrizes Curriculares Nacionais para este nível de ensino e faz parte das propostas do então Presidente da República Fernando Henrique Cardoso, que "expressam uma concepção de educação orgânica ao modelo econômico em curso, versão nacional do processo de globalização de acumulação flexível" (KUENZER, 2000, p. 16). Esse modelo se distancia de uma perspectiva de Ensino Médio Integral, onde a dicotomia ensino geral e ensino técnico-profissional seja superado.

\section{O EnSino MÉdio "INTEGRAdo" do governo LULA (2003/2010)}

Tendo abordado a geração anterior ao PT, mais afinada aos interesses neoliberais, nesta seção trataremos especialmente do governo do Presidente Luís Inácio "Lula" da Silva que em 2003, assume a condução do Estado brasileiro, e em seu primeiro mandato (2003-2006), basicamente deu continuidade à política econômica de seu antecessor Fernando Henrique Cardoso, com resultados de baixo incremento no PIB. Para Singer (2012, p. 74), a continuidade na "condução macroeconômica esteve baseada em três pilares: metas de inflação, câmbio flutuante e superávit primário nas contas públicas. Esta foi uma decisão política e ideológica" do governo Lula com o objetivo de assegurar a manutenção da ordem, elemento vital na conquista do apoio das camadas mais pobres.

Apesar de intensa propaganda sobre uma política industrial, essa não foi adiante, especialmente devido à prioridade na estabilização monetária. Já no segundo mandato (2007-2010), a peça básica da política econômica foi o Plano de Aceleração do Crescimento (PAC), que se concentra em investimentos de infraestrutura quando contrariamente "os estudiosos do desenvolvimento, como Hirschman, mostram que a infraestrutura 'permite', mas não 'determina' o desenvolvimento. O que impulsiona o desenvolvimento são as atividades diretamente produtivas" (MAGALHÃES, 2010, p. 22). Para este autor, o que de fato é importante na implantação do PAC é o reconhecimento, pela primeira vez nos últimos trinta anos, de que, "contrariamente a

\footnotetext{
${ }^{4}$ Capacidade do indivíduo manter-se ou inserir-se no mercado de trabalho, denotando que o mesmo desenvolva um conjunto de competências que facilite a mobilidade dos trabalhadores, para enfrentar a instabilidade do emprego (FRIGOTTO, 2008).

${ }^{5}$ São características marcantes desse modelo: liberalização, privatização e desregulação, subordinação e vulnerabilidade externa e estrutural e dominância do capital financeiro.
} 
tese neoliberal, a simples ação das forças do mercado não é suficiente para promover o crescimento acelerado do PIB. (MAGALHÃES, 2010, p.22). Em resumo, no que se refere ao desenvolvimento econômico tanto o governo Lula como seus antecessores, a partir da década de 1980, apresentaram um governo com forte tendência neoliberal, demonstrando que apesar da elevação da taxa de incremento do PIB, este não foi capaz de lançar o país na trilha do crescimento acelerado como já ocorrido em tempos passados.

Por outro lado, especialmente no segundo mandato, houve um aumento das taxas de crescimento da economia e redução do desemprego. Para Filgueiras et al. (2010), o "retorno" do Estado à esfera econômica recriou, muito embora que sob outras circunstâncias, o tripé capital internacional/Estado/Capital Nacional agora sob a hegemonia do capital financeiro. Neste caminho no Brasil, coerentemente com sua trajetória histórica de capitalismo retardatário, o capital nacional tem estreita ligação com o Estado o que garante a "organização e legitimação de um bloco de poder dominante". E devido a esse conjunto de situações, se vem chamando de "novo desenvolvimentismo", tendo como características principais a "dependência tecnológico-financeira, concentração de renda, exclusão social e democracia restrita". (FILGUEIRAS et al., 2010, p. 38-39).

No plano político, o governo Lula também não significou uma ruptura em relação aos seus antecessores. Como já citado, seu governo apresentou certas permanências e continuidades das políticas de cunho neoliberal desenvolvidas por seus antecessores, apesar de no seu governo o Estado ter um papel mais ativo, esse "retorno" teve o objetivo claro de fortalecimento do capital financeiro no Brasil, privilegiando assim os grandes grupos econômicos do país (privados e estatais). De modo que, as ações dos bancos oficiais e empresas estatais tem papel fundamental no cumprimento dessa tarefa. (FILGUEIRAS et al. 2010, p. 50).

Ainda no âmbito político, as práticas do governo Lula, em relação ao processo político-institucional e partidário, continuaram seguindo a tradição histórica no Brasil, qual seja: "estatização dos partidos no poder, cooptação fisiológica para formação de maiorias, patrimonialismo e esvaziamento das instâncias parlamentares, com o fortalecimento das agências governamentais executivas". (FILGUEIRAS et al., 2010, p. 51).

Já no âmbito social, seu governo aprofundou a adoção de políticas focalizadas como forma de atenuar os desequilíbrios causados pelo governo anterior. Nesse governo foram ampliados os números de bolsas de assistência social e no âmbito da educação foram criados vários programas "a fim de atingir a meta de um equilíbrio social assentado na ideia de ajustamento das ações dos diversos atores sociais" (FERREIRA, 2009, p. 258). Portanto, podemos inferir que ao mesmo tempo conviviam perspectivas progressistas e conservadoras nesse período representando um governo inscrito numa prática articulatória que não foi apenas de permanência do que estava sendo construído. 
DOI: $10.12957 / \mathrm{e}-\mathrm{mosaicos} .2020 .46488$

Em relação a educação, sua primeira ação mais significativa foi a criação do FUNDEB em 06 de dezembro de 2006 - Fundo de Manutenção e Desenvolvimento da Educação Básica e de Valorização dos Profissionais da Educação - com o objetivo de proporcionar a elevação e uma nova distribuição dos investimentos da educação. 0 antigo fundo (FUNDEF) vigorou até o fim de 2006, e permitia investimentos apenas no Ensino Fundamental, enquanto o novo fundo prevê investimentos da creche ao final do Ensino Médio e a Educação de Jovens e Adultos. O FUNDEB também trata da definição de um piso salarial nacional para os profissionais da escola pública.

Em seu governo, uma iniciativa que pode ser considerada como uma inovação em relação ao Ensino Médio foi a revogação do decreto 2.208/97 pelo decreto de lei $5.154 / 04$ e, depois, pela lei no $11.741 / 08$, o que naquele momento iniciou a possibilidade de uma nova política tanto para o Ensino Médio quanto para a Educação Profissional ordenando ações mais integradas entre ambos.

O ensino profissionalizante bem como o Ensino Médio estão na pauta das discussões sobre a educação dos jovens não só no Brasil, mas no mundo, principalmente devido às mudanças bruscas e sem precedentes das relações sociais capitalistas e das mudanças no mundo do trabalho a partir da adoção de políticas neoliberais especialmente a partir da década de 1970. No Brasil, com o objetivo de elevar os índices de conclusão no ensino médio regular, e buscando se equiparar aos países mais desenvolvidos, o Governo Federal apresenta novas proposições para essa etapa de ensino. Visto que, naquele momento, de acordo com a Síntese dos Indicadores Sociais divulgada pelo IBGE em $2010^{6}$, somente $37 \%$ dos jovens de 18 a 24 anos já completaram o Ensino Médio.

Assim, para aumentar os índices de conclusão e atender às demandas postas pelo mercado de trabalho, o MEC (Ministério da Educação) aposta na ampliação da educação profissional. O Governo Federal desde 2004 investe em propostas que apontem para um programa curricular mais flexível; uma das principais medidas é a possibilidade de integrar Ensinos regular e profissional, conforme indica o Decreto 5154/2004:

a Educação Profissional Técnica de nível Médio (...) será desenvolvida de forma articulada com o Ensino Médio, e que esta articulação entre a Educação Profissional Técnica de nível médio e o Ensino Médio "darse-á de forma integrada, concomitante e subsequente ao Ensino Médio (BRASIL, 2004, p.2).

Como já mencionado, o Governo Lula se inscreveu na articulação entre perspectivas políticas diferentes, assim o ensino médio integrado é resultado de um contexto contraditório e de disputa política e, portanto, representa um avanço em relação às políticas anteriores. De modo que, deve-se considerar as contradições e

\footnotetext{
${ }^{6}$ Disponível em: www.ibge.gov.br.
} 
mediações, sem as quais não seria possível compreender como essa política se materializou. Nesse sentido, assim como Frigotto (2015, p. 229) pensamos que essa política, no interior da análise fundamentada no materialismo histórico dialético, "sinaliza o mover-se na luta política no âmbito contraditório do velho e do novo e na perspectiva de superação da sociedade de classes". Ou seja, com Marx aprendemos que nosso ponto de chegada é a superação da sociedade capitalista e a construção de um novo tipo de sociedade se inicia ainda na velha estrutura social.

Compreendemos que a dualidade presente no Ensino Médio tem suas bases na relação capital/trabalho, ou seja, o problema está assentado sobre a dualidade estrutural da própria formação histórica da sociedade brasileira. E dessa forma as transformações necessárias vão sendo construídas a partir dos embates e disputas políticas de maneira que até a superação da sociedade capitalista vivenciamos momentos de avanços e retrocessos dessas políticas. Naquele momento o governo Lula que fora eleito com uma grande base social e apoio dos movimentos sociais permitindo, mesmo que de forma limitada, um avanço em relação à política para o ensino médio no Brasil.

Já em seu segundo, mandato sob a crítica de que as políticas educacionais de seu governo eram fragmentadas e sem efetividade na sua aplicação, o governo Lula lançou o Plano de Desenvolvimento da Educação (PDE), pautado numa visão sistêmica da educação. Fazem parte do PDE 40 programas, entre eles: o Prova Brasil (IDEB), com o objetivo de avaliar a qualidade do sistema de ensino brasileiro através de testes padronizados e questionários socioeconômicos; FIES (Fundo de Financiamento Estudantil), programa com o objetivo de financiar prioritariamente estudantes de cursos de graduação; IFETs (Institutos de Federais de Educação Tecnológica), PROUNI (Programa Universidade para Todos), criado em 2004 pela Lei no 11.096/05 cuja finalidade é a concessão de bolsas de estudos integrais e parciais a estudantes de cursos de graduação e de cursos sequenciais de formação específica. As instituições participantes do programa recebem isenção de tributos ${ }^{7}$.

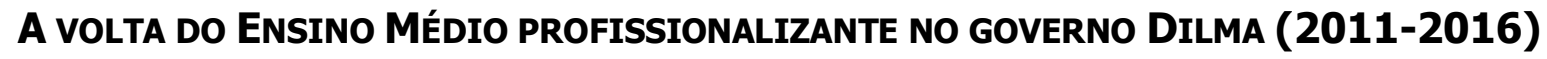

Nesta seção pretendemos apresentar um panorama das políticas educacionais para o Ensino Médio no governo Dilma. Nesse sentido, em 2010, é eleita a primeira mulher ao cargo máximo da República Federativa do Brasil, Dilma Vana Rousseff, candidata do Partido dos Trabalhadores (PT), e responsável em dar continuidade às políticas implantadas pelo governo anterior. Relativamente recebe o país com indicadores macroeconômicos satisfatórios, baixa taxa de desemprego, estabilidade de preços e bom desempenho do mercado de trabalho. Portanto, seu governo se inicia

\footnotetext{
${ }^{7}$ Disponível em: $\underline{w w w . p o r t a l . m e c . g o v . b r}$
} 
DOI: $10.12957 /$ e-mosaicos.2020.46488

com uma grande expectativa. Lembrando que naquele momento parecia que a grave crise de 2008 tinha sido contornada, não causando grandes prejuízos para o país.

No seu primeiro mandato, houve a intenção de continuidade da política conciliatória do seu antecessor, de modo que a política econômica nesse momento atendia a diversas bandeiras defendidas por setores importantes do empresariado brasileiro, inclusive da FIESP (Federação das Indústrias do Estado de São Paulo). Organização essa que mais tarde viria a ser um dos principais atores do impeachment chegando a financiar várias manifestações e construindo acampamento de militantes em frente a sua sede e tinha como lema "Não vamos pagar o pato!" bastante propagado. Chamada de "nova matriz econômica" a política econômica de seu primeiro mandato tinha as seguintes diretrizes: redução de taxas de juros e tarifas de energia elétrica; desonerações tributárias e crédito subsidiado; desvalorização cambial e protecionismo industrial seletivo; concessões de serviços públicos para a iniciativa privada. (BASTOS, 2017, p. 3). Muitas dessas iniciativas tinham sido solicitadas em documento assinado por diversas organizações empresariais, inclusive a FIESP em 2011.

Em um cenário de grande agitação política, no ano de 2014 a Presidente Dilma inicia o segundo mandato. Esse contexto de grande agitação começa a se delinear a partir das jornadas de junho de 2013, iniciadas em São Paulo e se espalhou pelo resto do país. Inicialmente os manifestantes se opunham ao aumento da passagem, de $\mathrm{R} \$$ 3,00 para $R \$ 3,20$, depois essa pauta se ampliou e era comum ver escrito nos muros e em cartazes a inscrição "não é por R\$ 0,20".

No segundo mandato, sua política econômica sofre algumas mudanças resolvendo realizar um brusco ajuste fiscal e monetário denotando a intenção em atender a exigências de certos setores empresariais críticos da "nova matriz econômica", para além das justificativas econômicas havia razões políticas que fundamentava essa virada. Por outro lado, a escolha do economista-chefe do principal banco privado do país (Bradesco) Joaquim Levy para o Ministério da Fazenda pareceu uma tentativa de retomar a política de conciliação tão bem desenvolvida por seu antecessor, Luís Inácio Lula da Silva, controlando a oposição dos empresários e criando um grande pacto do qual até a Federação Brasileira dos Bancos (FEBRABAN), cujos interesses foram atacados publicamente em 2012 pela Presidente, estava incluída. (BASTOS, 2017).

No entanto, aconteceu o contrário daquilo que se pretendia "ocorreu uma tendência de unificação da burguesia ou, pelo menos, de inação conivente do grande empresariado em torno da bandeira de impeachment de Dilma Roussef" (BASTOS, 2017, p.3) que em 2016 foi concretizado. Como a realidade mostrou a política de conciliação não deu certo, e um dos principais argumentos é de que a crise financeira global e as mudanças econômicas contribuíram para isso.

No que se refere às políticas educacionais, o grande investimento do governo Dilma Roussef foi a educação profissional, não apenas para a formação de mão de 
obra, mas como forma de melhorar a qualidade do Ensino Médio. Diferentemente do governo anterior, que investiu na expansão da rede federal de escolas técnicas, a proposta do governo Dilma inclui apoio às redes estaduais e à oferta de bolsas de estudos para alunos das escolas públicas estudarem em cursos profissionalizantes de instituições privadas. Assim, foi criado, em 26 de outubro de 2011 através da lei $n$. 12.513/2011, pelo então Ministro da Educação Fernando Haddad e pela Presidenta o PRONATEC (Programa Nacional de Acesso ao Ensino Técnico e Emprego) com o objetivo de "expandir, interiorizar e democratizar a oferta de cursos de formação inicial e continuada para trabalhadores, intensificar o programa de expansão de escolas técnicas em todo o país e melhorar a qualidade do Ensino Médio" (BRASIL, 2011).

O PRONATEC envolve um conjunto de iniciativas, entre elas o Programa Brasil Profissionalizado, cujo objetivo é fortalecer a educação profissional dos estados. A iniciativa repassa recursos federais para que sejam investidos em escolas técnicas. Criado em 2007, segundo o MEC, proporciona a possibilidade de modernização e expansão das redes públicas de Ensino Médio integradas à educação profissional, esta sendo uma das metas estabelecidas pelo PDE. Mais de $R \$ 1,5$ bilhão já foram repassados para os estados, através de convênios, com o objetivo de estimular a implementação de ensino médio. Outra ação que faz parte do PRONATEC é a Rede E-tec que tem como foco a oferta de cursos técnicos à distância, além da formação inicial e continuada de estudantes egressos do ensino médio ou da educação de jovens e adultos.

Além dessas iniciativas, o PRONATEC criou a Bolsa-Formação, por meio da qual seriam oferecidos cursos gratuitos para quem já concluiu o ensino médio, para aqueles que ainda estão cursando ou matriculados em cursos de formação inicial e continuada ou qualificação profissional. Os cursos são ofertados nas escolas públicas federais, estaduais e municipais, nas unidades de ensino do SENAI, do SENAC, do SENAR e do SENAT, em instituições privadas de ensino superior e de educação profissional técnica de nível médio ${ }^{8}$. Em 05 de junho de 2013, a Lei no 12.816/2013 alterou a Lei no $12.513 / 2011$ com o objetivo de ampliar os cursos de educação profissional e tecnológica e consequentemente para que isso ocorresse previa a ampliação de beneficiários e ofertantes da Bolsa-Formação Estudante.

Embora a expansão da educação profissional possa ser vista como um avanço relevante no que se refere às possibilidades de profissionalização dos jovens trabalhadores, é preciso atentar para o fato de que esse acesso por si só não é garantia de emprego, sob os auspícios do capitalismo flexível, que impõe o desemprego estrutural e a precarização do trabalho, como forma de garantir o processo de acumulação. (SILVA, 2012, p. 175). Nesse caso, o grande desafio é superar o projeto de educação profissional na perspectiva da pedagogia das competências e da empregabilidade. É possível afirmar que o Pronatec beneficiou as instituições privadas

\footnotetext{
${ }^{8}$ Disponível em: www.portal.mec.gov.br
} 
DOI: $10.12957 / \mathrm{e}-\mathrm{mosaicos} .2020 .46488$

de educação e nesse sentido quando em 2016, no governo Michel Temer, o programa foi finalizado esses grupos ficaram insatisfeitos.

No entanto, no último dia 08 de outubro de 2019 o MEC lança um novo programa chamado "Novos Caminhos", que prevê a regulação dos cursos pelas instituições privadas de Ensino Superior. Esse projeto de modo geral é uma cópia do Pronatec, que já tinha sido alvo de críticas durante a campanha eleitoral sobre o suposto desvio de dinheiro ${ }^{9}$.

Destacamos que durante os governos do Partido dos Trabalhadores houve avanços em relação as políticas educacionais, como ampliação da Rede Federal de Educação Profissional, Científica e Tecnológica, Programa de interiorização e abertura de novos campi das Universidades Federais, o Programa de Inclusão de JovensPROJOVEM e a criação do Fundo de Manutenção e Desenvolvimento da Educação Básica e de Valorização dos Profissionais da Educação - FUNDEB, entre outros. No entanto, acreditamos que essas mudanças não tiveram um alcance mais amplo e profundo, motivo pelo qual tão rapidamente muito daquilo que foi considerado como avanço tão rapidamente se perdeu. De modo que, acreditamos assim como Wood (2014), que "quaisquer que tenha sido as realizações progressivas alcançadas durante os governos de Lula e Dilma, elas foram severamente limitadas" e por isso, agora, talvez, estejam sendo revertidas numa grande velocidade.

\section{CONCLUSÃo}

Nesse breve caminho histórico que tentamos percorrer aqui, pudemos perceber como as políticas públicas para o Ensino Médio sofreram transformações importantes. Em dados momentos observamos avanços qualitativos no que diz respeito a um modelo de educação que acreditamos seja positiva, uma educação que alie ciência, cultura e formação geral para juventude. Em outros momentos podemos vislumbrar regressões, no sentido em que a formação da juventude não é pensada numa perspectiva de uma formação geral integrada a sua formação para o mundo do trabalho.

É importante destacar ainda que a separação entre Formação Geral e Formação Profissional aconteceu com a necessidade dentro do próprio processo produtivo de determinadas qualificações específicas que exigiam um preparo intelectual também específico, provocando a bifurcação do ensino: Escolas de Formação Geral e as Escolas Profissionais. Essa é, portanto, uma dualidade estrutural. A separação vem atendendo aos interesses do capital o que agravou ainda mais o quadro de desigualdades,

\footnotetext{
${ }^{9}$ No início do governo Bolsonaro o MEC chegou a anunciar a "Lava Jato" da educação e teria como objetivo identificar desvios no PRONATEC. Disponível em: http://educacao.estadao.com.br.
} 
DOI: $10.12957 / \mathrm{e}-\mathrm{mosaicos} .2020 .46488$

enfatizando as qualificações intelectuais em detrimento da qualificação específica, ou seja, a separação entre instrução e trabalho produtivo.

É no bojo da construção dessas políticas que a concepção sobre Ensino Médio vem ganhando corpo e demonstra a ideologia que dá sustentação a essa concepção. Compreender e elucidar como se deram as reformas educacionais e especificamente as reformas do Ensino Médio exige que as concepções sobre esse nível de ensino sejam desveladas para que os interesses e visões particulares de mundo próprias das diferentes posições de classe fiquem claras e que dessa forma se possa escolher dentro dos limites da democracia por possíveis históricos que são necessariamente contraditórios. (KUENZER, 2000).

É com este intuito que apresentamos esse breve histórico de como as demandas dos organismos internacionais teve repercussão no Brasil e se refletiram na elaboração das políticas educacionais brasileiras constituindo o escopo da criação das políticas educacionais para o Ensino Médio. Entendemos que, através desses ordenamentos, muito foi planejado, mas pouco foi feito, fato que provoca uma série de críticas sobre as contradições e ineficiências de tais ordenamentos. No entanto, é com base nesses dispositivos que vem ocorrendo a expansão do Ensino Médio. E que hoje vem sofrendo fortes ataques no que se refere aos avanços que foram alcançados ao longo desses anos isto graças a uma mudança na correlação de forças que compõe o poder político e econômico no Brasil.

\section{NOTA DO AUTOR}

Este artigo é fruto da Dissertação "Utilizações das Escolas de Referência em Ensino Médio pelo Governo do Estado de Pernambuco: uma análise do Programa de Educação Integral" defendida no âmbito da Universidade Federal de Pernambuco Centro Acadêmico do Agreste (UFPE-CAA) sob a orientação do Professor Doutor Jamerson Antônio Almeida da Silva.

\section{REFERÊNCIAS}

BRASIL. Constituição (1998). Constituição da República Federativa do Brasil: Promulgada em 5 de outubro de 1988. Senado Federal, Subsecretaria de Edições técnicas, Brasília, 2006.

. Lei de Diretrizes e Bases da Educação Nacional. Lei no 9394, de 20 de dezembro de 1996. Estabelece as diretrizes e bases da educação nacional. Senado Federal, Coordenação de Edições Técnicas, Brasília, 2017. 
DOI: $10.12957 / \mathrm{e}-\mathrm{mosaicos} .2020 .46488$

. Decreto no 5154, de 23 de julho de 2004. Regulamenta o § $2^{\circ}$ do art. 36 e os arts. 39 à 41 da Lei no 9.394, de 20 de dezembro de 1996, que estabelece as diretrizes e bases da educação nacional, e dá outras providências. Brasília, 2004.

. Lei no 11.741 de 16 de Julho de 2008. Altera dispositivos da Lei no 9.394, de 20 de dezembro de 1996, que estabelece as diretrizes e bases da educação nacional, para redimensionar, institucionalizar e integrar as ações da educação profissional técnica de nível médio, da educação de jovens e adultos e da educação profissional e tecnológica. Brasília, 2008.

. Lei 12.513 de 26 de Outubro de 2011. Institui o Programa Nacional de Acesso ao Ensino Técnico e Emprego (Pronatec); altera as Leis no 7.998, de 11 de janeiro de 1990, que regula o Programa do Seguro-Desemprego, o Abono Salarial e institui o Fundo de Amparo ao Trabalhador (FAT), no 8.212, de 24 de julho de 1991, que dispõe sobre a organização da Seguridade Social e institui Plano de Custeio, no 10.260, de 12 de julho de 2001, que dispõe sobre o Fundo de Financiamento ao Estudante do Ensino Superior, e no 11.129, de 30 de junho de 2005, que institui o Programa Nacional de Inclusão de Jovens (ProJovem); e dá outras providências. Brasília, 2011.

Lei 12.816 de 05 de Junho de 2013. Altera as Leis nos 12.513, de 26 de outubro de 2011, para ampliar o rol de beneficiários e ofertantes da Bolsa-Formação Estudante, no âmbito do PRONATEC; 9.250, de 26 de dezembro de 1995, para estabelecer que as bolsas recebidas pelos servidores das redes públicas de educação profissional, científica e tecnológica, no âmbito do Pronatec, não caracterizam contraprestação de serviços nem vantagem para o doador, para efeito do imposto sobre a renda; 8.212, de 24 de julho de 1991, para alterar as condições de incidência da contribuição previdenciária sobre planos educacionais e bolsas de estudo; e 6.687, de 17 de setembro de 1979, para permitir que a Fundação Joaquim Nabuco ofereça bolsas de estudo e pesquisa; dispõe sobre o apoio da União às redes públicas de educação básica na aquisição de veículos para o transporte escolar; e permite que os entes federados usem o registro de preços para a aquisição de bens e contratação de serviços em ações e projetos educacionais. Brasília, 2013.

. Lei n. 10.172, de 09 de Janeiro de 2001. Estabelece o Plano Nacional de Educação. Diário Oficial da União, Brasília, 2001.

. Resolução CEB No 3, de 26 de Junho de 1998. Institui as Diretrizes Curriculares Nacionais para o Ensino Médio. Diário Oficial da União, Brasília, 1998.

CIAVATTA, M.; FRIGOTTO, G. Perspectivas sociais e políticas da formação de nível médio: avanços e entraves nas suas modalidades. Educação e Sociedade. Vol. 32, n. 116. Campinas, jul/set 2011. Disponível em: http://cedes.unicamp.br 
DOI: $10.12957 /$ e-mosaicos.2020.46488

FERREIRA, E. B. Políticas educativas no Brasil no tempo da crise. In: FERREIRA, E. B.; OLIVEIRA, D. A. (orgs.). Crise da Escola e Políticas Educativas. Belo Horizonte: Autêntica, 2009.

. Ensino Médio no Brasil: os desafios das políticas de garantia do direito a sua universalização. Linhas Críticas. Vol. 17, n. 34, p. 507-525. Brasília, set./dez. 2011.

FILGUEIRAS, L. et al. Modelo liberal-periférico e bloco de poder: política e dinâmica macroeconômica nos governos Lula. In: MAGALHÃES, J. P. de A. (org.). Os anos Lula: Contribuições para um balanço crítico 2003-2010. Rio de Janeiro: Garamond, 2010.

FRIGOTTO, G. Educação, crise do trabalho assalariado e do desenvolvimento: teorias em conflitos. In: FRIGOTTO, G. (org.). Educação e Crise do trabalho: Perspectivas de final de século. Petrópolis, RJ: Vozes, 2008.

. A produtividade da escola improdutiva 30 anos depois: regressão social e hegemonia às avessas. Trabalho Necessário. Ano 13, n. 20, p. 206-233. Rio de Janeiro, 2015.

KUENZER, A. Z. O Ensino Médio agora é para a vida: entre o pretendido, o dito e o feito. Educação e Sociedade. Campinas-SP, v. 21, n. 70, p. 15-39, abril/2000. Disponível em: http://cedes.unicamp.br

. O Ensino Médio no plano nacional de educação 2011-2020: superando a década perdida? Educação e Sociedade. Campinas-SP, v. 31, n. 112, p. 851-873, julset/2010. Disponível em: http://cedes.unicamp.br.

MAGALHÃES, J. P. de A. Estratégias e modelos de desenvolvimento. In: MAGALHÃES, J. P. de A. (org.). Os anos Lula: Contribuições para um balanço crítico 2003-2010. Rio de Janeiro: Garamond, 2010.

MBEMBE, A. Necropolítica. Revista do PPGAV/EBA/UFRJ. Rio de Janeiro, n.32, p. 123151, dez/2016. Disponível em: http://revistas.ufrj.br

NOSELLA, P. Ensino Médio: Em busca do princípio pedagógico. Educação e Sociedade. Campinas-SP, v. 32, n. 117, p. 1051-1066, out-dez/2011. Disponível em: http://cedes.unicamp.br

RAMOS, M. O projeto unitário de ensino médio sob os princípios do trabalho, da ciência e da cultura. In: CIAVATTA, M.; FRIGOTTO, G. (orgs). Ensino Médio: ciência, cultura e trabalho. Brasília: Ministério da Educação, 2004. 
DOI: $10.12957 /$ e-mosaicos.2020.46488

A Pedagogia das Competências: autonomia ou adaptação? 3. ed. São Paulo:

Cortez, 2006.

. Ensino médio integrado: ciência, trabalho e cultura na relação entre educação profissional e educação básica. In: MOLL, Jaqueline. Educação profissional e tecnológica no Brasil contemporâneo. São Paulo: Artmed, 2010.

- O currículo para o ensino médio em suas diferentes modalidades:

concepções, propostas e problemas. Educação e Sociedade. Campinas-SP, v. 32, n. 116, p. 771-788, jul/set/2011.

SAVIANI, D. A nova lei da educação: LDB, limite, trajetória e perspectivas. São Paulo: Autores Associados, 1997.

SILVA, J. A. A. As especificidades das políticas de qualificação profissional para a juventude. In: OLIVEIRA, R. (org.). Jovens, Ensino Médio e Educação Profissional: Políticas públicas em debate. Campinas, SP: Papirus, 2012.

SINGER, A. Os Sentidos do Lulismo: Reforma gradual e pacto conservador. São Paulo: Companhia das Letras, 2012.

WOOD, E. M. O Império do Capital. São Paulo: Boitempo, 2014.

Recebido em 05 de novembro de 2019

Aceito em 11 de abril de 2020

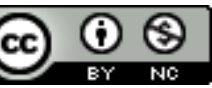

A e-Mosaicos Revista Multidisciplinar de Ensino, Pesquisa, Extensão e Cultura do Instituto de Aplicação Fernando Rodrigues da Silveira (CAp-UERJ) está licenciada com uma Licença Creative Commons - Atribuição-NãoComercial 4.0 Internacional.

Os direitos autorais de todos os trabalhos publicados na revista pertencem ao(s) seu(s) autor(es) e coautor(es), com o direito de primeira publicação cedido à e-Mosaicos.

Os artigos publicados são de acesso público, de uso gratuito, com atribuição de autoria obrigatória, para aplicações de finalidade educacional e não-comercial, de acordo com o modelo de licenciamento Creative Commons adotado pela revista. 